\title{
Transtympanic balloon dilatation of the eustachian tube: systematic review - CORRIGENDUM
}

\author{
N JUFAS, N PATEL
}

doi:10.1017/S0022215116000918, first published online by Cambridge University Press, 11 March 2016

In the above published paper (Jufas and Patel 2016), the asterisks in Figure 1(b) on page 427 were shown in the wrong position. The correct version of Figure 1(b) is shown below.

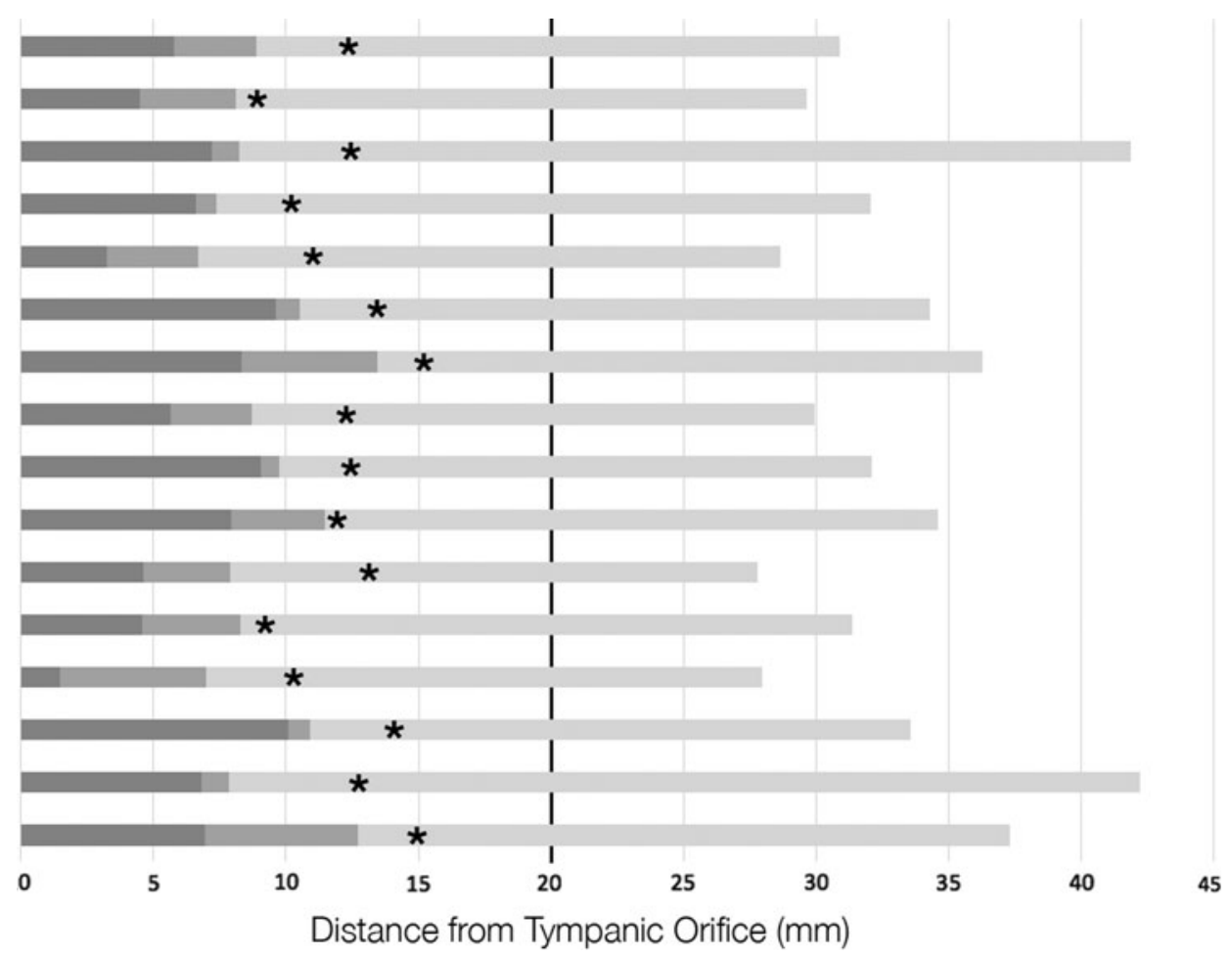

Reference

N Jufas and N Patel (2016). Transtympanic balloon dilatation of the eustachian tube: systematic review. The Journal of Laryngology \& Otology, 130, pp 425-430. 